Science, Technology and Development 35 (2): 63-66, 2016

ISSN 0254-6418 / DOI: 10.3923/std.2016.63.66

(C) 2016 Pakistan Council for Science and Technology

\title{
Current Status of Research and Development in the SAARC Region
}

\author{
Aftab Ahmad, Sadia Ashraf and Zaigham Abbas \\ National Academy of Young Scientists (NAYS), University of the Punjab, \\ Quaid-i-Azam Campus, Lahore, Pakistan
}

\begin{abstract}
South Asian Association for Regional Cooperation (SAARC) comprises 8 countries in South Asian region, which constitutes $22 \%$ of the world and $40 \%$ of developing world population. The whole, SAARC region produced 114, 192 citable research articles in 2013, which comprise $4.14 \%$ of the world share. Among these 98,968 (3.6\%) were just produced by India. In the same year, Japan produced 114, 592 articles with a global share of $4.17 \%$, which is even higher than whole SAARC region, while China's share was $15.17 \%$ with 416,292 research documents. As the research publications share from SAARC region is very small as compared to the rest of the world, there is great need to have more investment in the area of research and development as well as a greater regional and international collaboration.
\end{abstract}

Key words: SAARC, research and development, publications, science and technology

\section{INTRODUCTION}

Research plays a crucial role for the economic development of any country and has an important role in improving quality of life, living standards and social wellbeing (Ahmad et al., 2014a; Meo et al., 2013). In the present era, no country can deny the importance of education, science and technology and almost all countries are making their best efforts to promote them. In addition, investments are on an increase in research and development in most of the countries of the world. The countries across East and Southeast Asia are increasing their research and development budget, which is stimulating their scientific endeavors. The Asian countries, especially China, Japan and South Korea, have substantially increased their research and development budget and so their number of publications are also on an increase (Anonymous, 2014). The South Asian Association for Regional Cooperation (SAARC) comprises eight countries namely Afghanistan, Bangladesh, Bhutan, India, Maldives, Nepal, Pakistan and Sri Lanka and these countries make around 22\% of the whole world population (1.56 billion). Among SAARC countries, three countries, including India, Pakistan and Bangladesh, are among the 10 most populous countries of the world. The whole region comprises almost $40 \%$ of the developing world as all the 8 countries in SAARC region are called as developing countries (Feigin et al., 2009; Wasay et al., 2014).

For the scientific progress in the world, research publications are very important. In addition, scientific publications are also an important indicator of the development of any country. Those countries which provide a healthy scientific and research environment show scientific and economic progress (Meo et al., 2013). The status of research output from SAARC countries in the form of publications in well reputed journals and overall publications from the region will be highlighted in this study.

\section{MATERIALS AND METHODS}

Nature index: Nature has recently produced its index on the basis of article published in high quality journals (68 leading journals) from 6 regions of the world and in 4 major subject categories, including chemical sciences, earth and environmental sciences, physical sciences and life sciences. They included all the articles published from 1st October, 2013-30th September, 2014 and indexed them to give institutional and country output on the basis of Article Count (AC), Fractional Count (FC) and Weighted Fractional Count (WFC). The data for SAARC and representative Asian countries was collected from Nature index website (www.natureindex.com).

Total publications: The data related to total publications was collected from SciMago website (www.scimagojr.com) for the year 2013 in country ranking categories and included only citable articles with $\mathrm{H}$ index. The data was recorded and analyzed statistically on MS Excel 2010, including the percentage of the world share and total publications.

\section{RESULTS AND DISCUSSION}

Nature index: According to nature index article count, in SAARC region, India produced a maximum number of publications with Article Count (AC) of 1,514 and 
Sci. Technol. Dev., 35 (2): 63-66, 2016
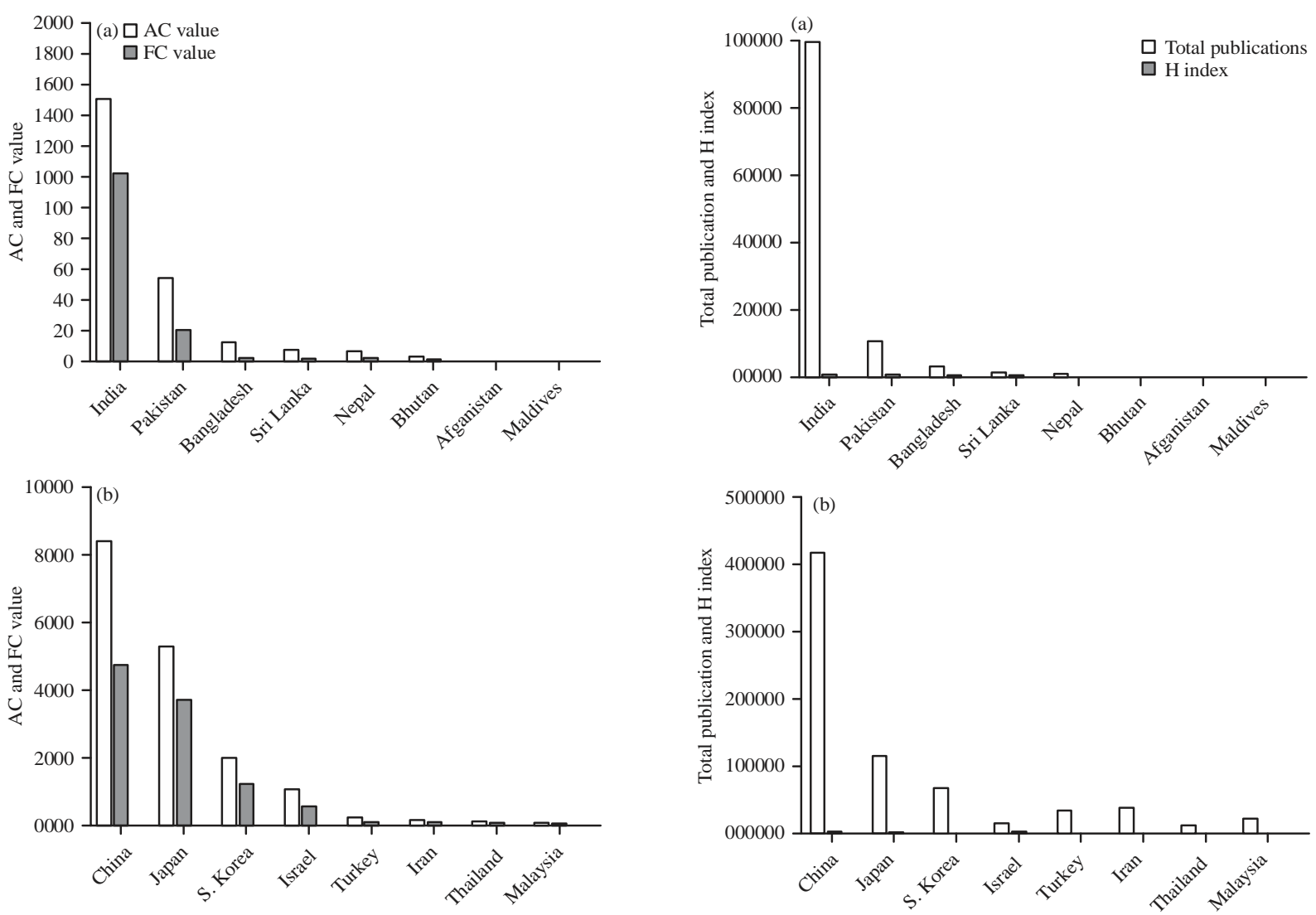

Fig. 1(a-b): Total number of AC and (a) FC from SAARC and (b) Representative Asian countries in Nature index from October, 2013-September, 2014 in representative 68 journals

Fractional Count (FC) of 1,039 followed by Pakistan with AC of 53 and FC of 19.88, while Afghanistan and Maldives could not produce a single publication in 68 leading journals from October, 2013-September, 2014. When a comparison was done with other Asian countries, it was found that China produced 8,380 articles followed by Japan, which produced 5,278 and the number of articles from South Korea was 1,973 (Fig. 1). The total numbers of nature index articles from South Korea were even more than the total number of nature indexed articles from whole SAARC region (Table 1).

Total publications: The total citable number of publications from the whole SAARC region in the year 2013 were 114,192 and once again India was the leading publishing country with the total number of articles 98,698, followed by Pakistan with 10,493 and the least No. of articles was from Maldives, which could only produce 15 articles (Table 1, Fig. 2).

In the same year, from other Asian countries, China published 416,292 articles followed by Japan which produced 114,592 . It is noteworthy here that the

Fig. 2(a-b): Total number of publications and $\mathrm{H}$ index from SAARC (a) Countries and (b) Representative Asian countries, in the year 2013

number of articles from Japan only, were more than the total number of articles from the SAARC region (Table 1 , Fig. 2).

Comparing the world share of publications, it was found that India had maximum share of $3.6 \%$ from SAARC region, while all the other countries from SAARC region had less than $1 \%$ share and total share from SAARC region in publications was $4.14 \%$ while China alone had $15.17 \%$ of world share of publication in the year 2013 followed by Japan which had 4.17\% and once again Japan only, had more world share in publication than whole SAARC region which had 4.14\% (Fig. 3).

Although, the South Asian countries constitute $22 \%$ of world population but the total scientific output from the region is very low, which is merely $4.14 \%$ of world share. As compared to all SAARC countries, a single country, Japan which has a population of 127 million (2014) (12 times less than that of south Asian countries) has more scientific output than the whole SAARC region, which truly indicates the commitment for 
Sci. Technol. Dev., 35 (2): 63-66, 2016

Table 1: Total No. of publications and publications in nature index from SAARC region and representative Asian countries

\begin{tabular}{lllrrr}
\hline Country name & AC* & FC** & Total publications*** & H index & Percentage world share \\
\hline India & 1514 & 1039.49 & 98,968 & 341 & 3.60 \\
Pakistan & 53 & 19.88 & 10,493 & 130 & 0.38 \\
Bangladesh & 12 & 1.94 & 2,796 & 112 & 0.10 \\
Sri Lanka & 7 & 1.02 & 1,057 & 96 & 0.038 \\
Nepal & 6 & 1.79 & 737 & 80 & 0.026 \\
Bhutan & 3 & 0.56 & 62 & 20 & 0.002 \\
Afghanistan & 0 & 0 & 64 & 24 & 0.002 \\
Maldives & 0 & 0 & 15 & 18 & 0.0005 \\
Total & 1,595 & $1,064.68$ & 114,192 & 821 & 4.14 \\
Representative Asian countries & & & & 436 & 15.17 \\
China & 8,380 & $4,728.86$ & 416,292 & 694 & \\
Japan & 5,278 & $3,691.97$ & 114,592 & 375 & 2.47 \\
S. Korea & 1,973 & $1,241.06$ & 67,783 & 456 & 0.58 \\
Israel & 1,021 & 547.91 & 15,919 & 237 & 1.25 \\
Turkey & 231 & 92.5 & 34,462 & 158 & 1.36 \\
Iran & 139 & 77.17 & 37,313 & 190 & 0.39 \\
Thailand & 91 & 27.82 & 10,805 & 145 & 0.82 \\
Malaysia & 60 & 17.02 & 22,497 & 2,691 & \\
Total & 17,173 & 10,424 & 719,663 &
\end{tabular}

*AC: Where a count of one is assigned to an institution or country if one or more authors of the research article are from that institution or country, regardless of how many co-authors there are from outside that institution or country, ${ }^{* *} \mathrm{FC}$ : That takes into account the percentage of authors from that institution (or country) and the number of affiliated institutions per article. For calculation of the FC, all authors are considered to have contributed equally to the article. The maximum combinedFCfor any article is 1.0, ***Data source for total publications and $\mathrm{H}$ index: http://www.scimagojr.com/countryrank.php
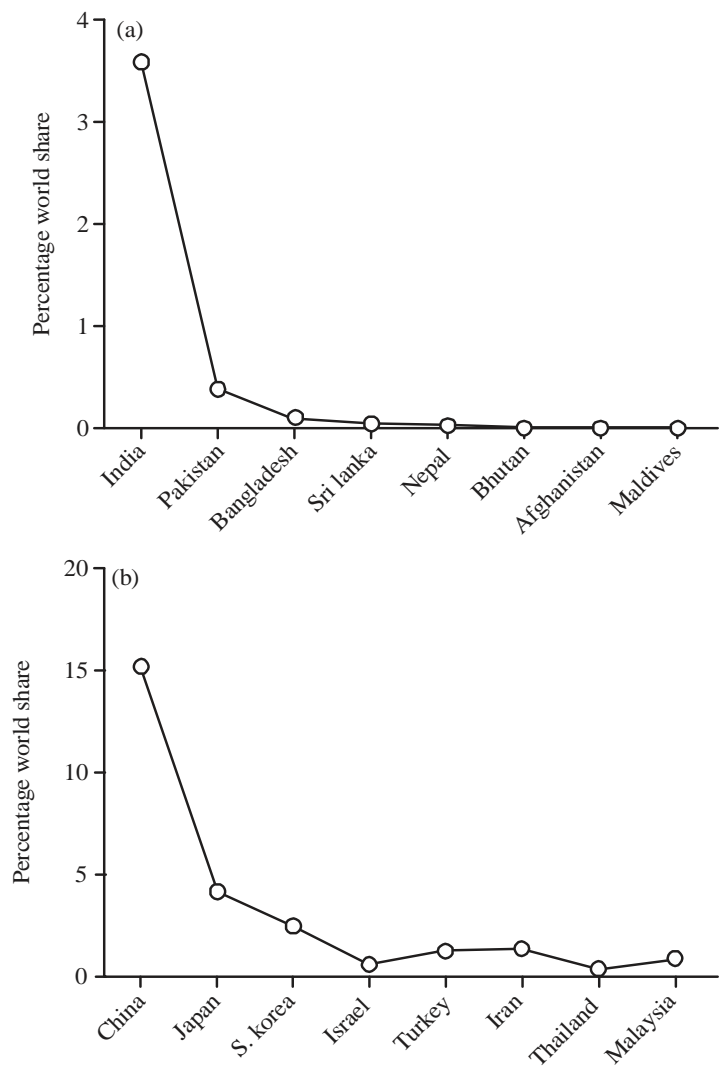

Fig. 3(a-b): World share in publication from SAARC (a) Countries and (b) Representative Asian countries, as percentage world share, in the year 2013 education, science and technology (Anonymous, 2014; Wasay et al., 2014).

Among the Asian countries, China and Japan are the world's 2nd and 3rd countries that spend maximum on research while South Korea is the 5th and is expected to spend 63 billion USD on research and development. This is the reason why these countries have such an enormous contribution in science and their total scientific output in the form of citable scientific publications in 2013 was $15.17,4.17$ and $2.47 \%$ of the world share, respectively (Anonymous, 2014). In addition to these, Iran and Turkey, which are also developing countries in Asia, contributed 1.36 and $1.25 \%$ of the world share in scientific publication in the year 2013, while India contributed $3.6 \%$ of the world share. The overall contribution from China, Japan and South Korea is much higher as compared to SAARC countries.

The trend of collaborative research work among the south Asian countries is very less and of the total $1,042,846$ articles produced by the region from $1964-2013$, only $16.5 \%$ had research collaboration among at least 2 countries while just $2.2 \%$ of total publications had collaboration among the south Asian countries, while outside SAARC, maximum collaboration was found with US (20\%) and UK (8\%). Overall, the world share of SAARC region in the form of research publications is 2.86\% in the last 50 years (Uddin and Singh, 2014).

A comparison of the research output (per million population of the SAARC region) during 2004-2013 revealed that India was taking the lead by publishing 
596 articles per million population, while Pakistan, Sri Lanka, Nepal, Bangladesh, Maldives, Bhutan and Afghanistan produced 418, 372, 174, 140, 82, 53 and 1.3 articles per million population, respectively. Overall India is producing almost $90 \%$ of publications from the region but it also has a population of over 1240 million (2011) (Uddin and Singh, 2014). As listed in Table 1 as well, that India's contribution in the world share was $3.6 \%$ in 2013, while SAARC region's share was just $0.54 \%$.

Furthermore, the total Impact Factor (IF) journals from SAARC region are just 118 and among these 100 are from India, 12 from Pakistan, 4 from Bangladesh and one each from Nepal and Sri Lanka, while there is no IF journal from Bhutan, Afghanistan and Maldives yet, so there is also a need to increase the number of good quality journals from the SAARC region (Ahmad et al., 2014b).

\section{CONCLUSION}

Overall the research output from SAARC region is very low compared to the population share in the world, which highlights the need for more investment in the area of education, research and development as well as more collaboration in the region as well as in the world. In addition, there is also a need to learn from the successful examples of other Asian countries, like China, Japan and South Korea, which have high investment in science and development and they are not only having good science publication but they are becoming technology hubs in the world.

\section{REFERENCES}

Ahmad, A., S. Aryal and S. Sarkar, 2014a. Current status of microbiology and medical microbiology research in SAARC countries. Int. J. Microbiol. Allied Sci., 1: 10-15.

Ahmad, A., S. Ashraf, A. Raheem and A. Yasmeen, 2014b. Science, scientists and economic growth. Sci. Technol. Dev., 33: 165-168.

Anonymous, 2014. East and Southeast Asia. Nature, 515: S73-S75.

Feigin, V.L., C.M. Lawes, D.A. Bennett, S.L. Barker-Collo and V. Parag, 2009. Worldwide stroke incidence and early case fatality reported in 56 population-based studies: A systematic review. Lancet Neurol., 8: 355-369.

Meo, S.A., A.A. Al Masri, A.M. Usmani, A.N. Memon and S.Z. Zaidi, 2013. Impact of GDP, spending on $\mathrm{R} \& \mathrm{D}$, number of universities and scientific journals on research publications among Asian countries. PLoS ONE, Vol. 8. 10.1371/journal.pone.0066449.

Uddin, A. and V.K. Singh, 2014. Measuring research output and collaboration in South Asian countries. Curr. Sci., 107: 31-38.

Wasay, M., I.A. Khatri and S. Kaul, 2014. Stroke in South Asian countries. Nat. Rev. Neurol., 10: $135-143$. 